\title{
Career Planning Mode and System Design of University Freshmen
}

\author{
Weiwei $\mathrm{Li}^{1}$, Caihong Huangfu ${ }^{1}$ \\ ${ }^{1}$ Department of Electrical Engineering and Automation, Henan Polytechnic University, JiaoZuo, Henan, China
}

\begin{abstract}
Career planning plays important role in personal development, but it is still a novelty to many university freshmen, since the vast majority of students begin choosing their occupational direction just before graduation. This research investigates the necessity, mode and system design of career planning of university freshmen, and point out that the university should cultivate the professional interests and occupational competition of students, so as to establish unique career plan for their occupational selection and development.
\end{abstract}

Keywords: Career planning mode; system design; university freshmen

\section{Introduction}

Career is the accumulation and result of the roles one person plays in his or her life, and career planning consists of many aspects including study, livelihood and work. Career planning is a novelty to university freshmen, since the vast majority of students begin choosing their occupational direction just before graduation. This must be changed! We should cultivate their awareness of career planning from the beginning through freshmen education, cultivate their professional interests based on their own characteristics, promote their competitiveness for seeking appropriate jobs, so as to prepare them for occupational selection and development. ${ }^{1-2]}$

Career planning of university freshmen is a process of self-recognition, environment recognition and cultivation of ability of occupational selection under guidance of counselor or other professionals based on their physical and mental characteristics. Students will be able to determine their development goal and path through career planning, and well adapt to their career development. ${ }^{[3]}$

\section{The necessity of career planning}

Many problems such as lack of goal or maladjustment may occur to university freshmen, so we need to solve these problems through comprehensive education means. Career planning not only can help the freshmen with their maladjustment problems but also can promote their university planning and the future career development. Career planning means a lot to the lifetime development of students, so it's particularly important and urgent.

\subsection{Object loss is common}

High school students are mainly under supervision of their parents and they have clear objectiveness of going to the college. But after becoming college students they can't get helpful suggestions on future development and occupational direction, and many of them want to relax for some time. Since they lack of pressure and motivation, they may lost their goals in short even long term.

Many students have high expectation and great imagination of college lives after the college entrance examination. But they gradually feel the distance between reality and dream, and they can't find an obvious goal when facing complex things such as studies, work, livelihood, sentiment and social relationship.

\subsection{Maladjustment of freshmen}

It's an important turning point from high school to college, at which the freshmen can't adapt to new environment and learning method, therefore feel confused. In high school, the students spend most of their time on courses, but association and communication with other schoolmates are less. There are complex human relationships in college so that each student must learn to adapt.

Teaching in college is most different with in high school, which focus on the ability of research and selflearning. Teachers give guidance and inspiration, and students must self-study and think independently. There are dramatic changes in study goal, content, method and type, so the passive learning mode can't adapt to college study any more, and many students have maladjustment problem.

\subsection{Freshman year is critical}

From elementary school to high school the development route of students have been planned by their parents, but there are so many things they have to pay attention to on their own in college. Depression, confusion and lost are the most frequently used words for describing college life of freshmen, so the first year in college is critical to career planning. ${ }^{[4]}$

College students with active thinking and vigor are pleased to accept new things and to be guided. The study pressure is less, so they begin to absorb diverse information actively. They wish to have efficient guidance to determine occupational direction and goal. 


\section{Major career planning mode}

\subsection{Penetrate through profession planning}

Most freshmen don't have recognition and initiative for career planning, so we must penetrate into career planning through profession planning. The first thing which freshmen face to is profession study, and the students are curious but also confused about the totally new knowledge. If we start with profession introduction and future development, then students may feel very helpful. [5]

During the career planning education of freshmen, we should teach them to understand the knowledge hierarchy, the goal of cultivating talents and career prospects of their profession. They must determine study goals based on profession and personal characteristics, so as to spread employment chances and form reasonable career conception.

\subsection{Centralize to clear goal}

One of the goals of college education is to help the students finding appropriate and satisfying job after graduation. Therefore each student must think specifically about what to do in college based on their personal conditions.

Comprehensive education activities and chances must be provided for students, including career planning assessment, education activities, workshop and small special seminars. We should guide students to prepare for exploration of career and understand the expectation of employers and recruit procedure. The most important thing is to help them recognize their common abilities, and then set their career goal after assessing advantages and skills. Interests and new skills will be developed through different courses and education activities. The students begin to focus on their employment competitiveness and occupational development, so as to lay solid foundation for practical employment. ${ }^{[6-7]}$

\subsection{Emphasize on inspiring ideals}

The expectation for future development of each student must be inspired through their ideals on which they insist. From this point of view, career planning equals to ideal cultivation for freshmen, and it's more realistic and honorable. The difficulty is that most students have forgotten or lost their own ideals during traditional education process. So the totally new life in a new environment is helpful for them to pursue their dreams.

We should help the students to set up great ideals and clear life goals, and guide them from future ideals (ultimate) to short-term ideals (5 years) then to current plans (this term or this week), so as to make their ideals gradually clear and vivid - which are real guidance and promotion for them. For example, we can provide symposium about the ideal, goal, professional development and life attitude for all the freshmen to help them setting up great ambitions.

\subsection{Introduce peer counseling}

Typically people have deep impression about the "firsttime" things according to psychological primacy effect. Career planning education intrinsically is education based on personal wisdom, because everyone has his unique characteristics. So the students can gain mostly only through their own experiences. That's why we need to apply various types of activities such as role model interview and psychological evaluation etc.

We can invite some past graduate students who have extraordinary study or occupation developments to introduce their experiences and feelings, which can increase the career planning education effect. Since they have similar environment it will be easier to copy and generate motivation to make some active moves.

\section{Career planning system design}

\subsection{Increase adaptability of freshmen}

The biggest challenge to which freshmen face is the transition from high-school to university studies, and whether they can successfully complete university life depends on this to a great degree. So we provide psychological evaluation to freshmen and record and document their psychological status, and organize group psychological counseling to help them resolving psychological problems and increasing their adaptability.

Experience exchange meeting between freshmen and senior students is very important for freshmen to master study method, make clear goal, set-up self-learning concept and increase adaptability. Dormitory culture development and rich and varied recreational activities are great for make freshmen familiar with each other and comfortable with new environment and social relationships. ${ }^{[8]}$

\subsection{Increase self-recognition level of freshmen}

Professional counselors are arranged to teach career planning courses for freshmen. In these courses theoretical knowledge and practical method will be introduced, and the teacher will lead the students to recognize themselves and learn to use evaluation tools. After that the freshmen will be able to correctly evaluate their value, interests, technique, self-recognition and failures. ${ }^{[9]}$

Class-wide meetings which focus on "what can I do?" and "what should I do?" are helpful for the students to understand and recognize themselves. Experience exchange meeting between freshmen and senior students is a great platform for them to communicate with classmates and recognize individual characteristics such as personality, nature, ability and sense of worth. 


\subsection{Increase environment familiarity of freshmen}

School history education activities such as knowledge competition and history museum visit are helpful for the freshmen to increase their sense of identity and belonging. Education, teaching and regular management policy propaganda is useful to lead them to understand completely and clearly school rules. Through profession introduction and rap session between students and school leaders the freshmen can deeply understand the profession, future prospects, market requirement and social meaning, so as to inspire their professional interests.

\subsection{Establish multi-level career planning education system}

Role model education is important to motivate the freshmen to actively seek career development chances. Role models in the same school are helpful for them to set up goals, learn to be independent in life and make clear career plans based on their own characteristics and social requirements.

Profession recognition education can be used to explore professional world and establish individual occupational preferences. The students will be able to determine the direction of their quality and ability cultivation, and make customized career development plan.

Career planning education is an effective way to lead the students to explore themselves and the environment. They will complete a perfect career planning report with personalized counseling. ${ }^{[10]}$

\section{CONCLUSIONS}

Complete career planning mode for college freshmen based on course planning, professional guide, ideal cultivation and comprehensive practical activities is promoted, multilevel career planning system which focuses on adaptability, self-recognition level and professional awareness is established, so as to guide college freshmen to adapt to college life and seek goals and make great professional choice and development.

\section{References}

[1] Dong Chunhua, "The enlightenment of American's college career planning education to China's universities employment instruction work", Journal of Employment Guidance, pp. 45-48, 2012 (16).

[2] Liu Cuicui, Xia Xiaogang, "The investigation and analyze of college students' career planning", Journal of University Education, pp. 133-134, 2013(8).

[3] Zou Hao, Zeng Hengyang, "Thoughts on enhancing effectiveness of career planning education for freshmen at institutions of higher learning", Journal of South China University of Technology(Social Science Edition), vol. 14, pp. 151-154, 2012.

[4] Cui Bin, "Personal background, career planning education and college students employment", Conference on Creative Education, pp. 114-117, 2013.

[5] Wang Jue, "The survey and countermeasure research of the career planning of the freshmen of science and engineering major", Journal of Chinese Employment of College Students, pp. 59-63, 2013(6).

[6] Zhou Xiaole, Jia Yang, "The survey and countermeasure research of career planning of engineering students", Journal of Continuing Education Research, pp. 126-127, 2013(1).

[7] Zhang Xudong, Xia Hui, "A novel teaching mode based on experience", Journal of Research on Teaching, vol. 36, pp. 71-76, 2013.

[8] Pang Feng, "The exploration of teaching methods of college students' career planning course under the new situation", International Conference on Education and Teaching, pp. 127-129, 2013.

[9] Bian Fang, Zhu Jixiang, "Wise to fast and first regulate, successful to start and draw new dreamprogrammed the freshmen for career planning", International Conference on Education Reform and Management Innovation, pp. 287-290, 2012.

[10] Guo Jing, "The study about the influence of the college students' career planning and design on the their employment status", International Conference on Education Science and Management Engineering, pp.672-673 , 2011. 